\title{
A Rare EGFR R748T Mutation in A Squamous Cell Lung Carcinoma Patient with PD-L1 High Expression and Response to Immuno-Chemo Combination Therapy
}

\section{Ruifang Sun}

Department of Pathology, School of Basic Medical Sciences, Xi'an Jiaotong University Health Science Center

\section{Qianqian Duan}

State Key Laboratory of Translational Medicine and Innovative Drug Development, Jiangsu Simcere Diagnostics Co., Ltd.

\section{Guangyan Lei}

Department of Thoracic Surgery, Shaanxi Provincial Tumor Hospital, Xi'an Jiaotong University Zhigang Liu ( $D$ lzg1103@163.com)

Department of Thoracic Surgery, Shaanxi Provincial Tumor Hospital, Xi'an Jiaotong University

\section{Case report}

Keywords: immuno-chemo therapy, EGFR rare mutation, PD-L1

Posted Date: September 4th, 2020

DOI: https://doi.org/10.21203/rs.3.rs-68851/v1

License: (c) (i) This work is licensed under a Creative Commons Attribution 4.0 International License.

Read Full License 


\section{Abstract}

Background: In present, patients with stage IV or recurrent/metastatic non-small cell lung cancer (NSCLC) whose tumors harbor programmed death ligand 1 (PD-L1) expression and active Epidermal Growth Factor Receptor (EGFR) mutations should receive initial EGFR tyrosine kinase inhibitors (TKIs) based on clinical guidelines and practice. However, high PD-L1 expression correlates with primary resistance to EGFR-TKIs in treatment advanced EGFR-mutant lung cancer patients, the optimal use of ICl therapy in patients with actionable EGFR mutations remains an important field of ongoing research. Some studies also showed that patients with uncommon EGFR mutations have a good immunotherapy potential.

Case prestation: Here, we report a 56-year old advanced squamous cell lung carcinoma (SCC) patient with a rare active mutation in EGFR gene (EGFR p.R748T) and PD-L1 expression who responded well to the immune-chemo combination therapy (pembrolizumab with nab-paclitaxel and nedaplatin).

Conclusion: The EGFR R748T mutation is an uncommon active mutation and there is no report about immuno-chemo therapy on patient with EGFR R748T mutation and PD-L1 high expression. The result presented in this case provides a feasible therapy for some patients who harbor rare active EGFR mutations (except for G719X, L861Q, S768I, and Ex20 ins) with high PD-L1 expression.

\section{Background}

Targeted therapies and more recently immune checkpoint inhibitors (ICls) have transformed the treatment landscape of advanced NSCLC [1]. However, the activity of ICls across NSCLC harboring oncogenic alterations is poorly characterized. On the one hand, patients with oncogene-driven NSCLC such as EGFR, ALK always have been left behind-either excluded from pivotal immunotherapy clinical trials or demonstrated lack of efficacy to immune checkpoint blockade [2,3]. On the other hand, targeted therapies are efficient in the context of oncogenic driver mutations [4]. But unfortunately, target therapies are associated not only with high response rate, but also with unavoidable development of resistance and tumor recurrence. Meanwhile, it has been reported that the high expression of PD-L1 was a factor of primary EGFR-TKI resistance $[5,6]$. In present, some studies have shown that different EGFR subtypes responded differently to immunotherapy, some rare EGFR mutations have immunotherapy potential [79]. Therefore, after exhaustion of targeted agents or naïve advanced EGFR-mutant with PD-L1 high expression, immunotherapy may be considered as a salvage treatment. In this case report, we presented a squamous cell lung carcinoma (SCC) patient with a rare active EGFR p.R748T mutation and PD-L1 high expression who benefited from combination pembrolizumab with nab-paclitaxel and nedaplatin.

\section{Case Presentation}

A 56-year old men with history of smoking was admitted to our hospital with complaints of irregular coughing and fever. Nucleic acid test result was negative. The patient then had a thoracic computed tomography (CT) scan, which revealed a lesion in the lower lobe of the right lung and some pleural 
effusion. Transbronchoscopic needle aspiration biopsy indicated SCC and immunohistochemistry (IHC) revealed AE1/AE3 (+), Ki-67 (partial about 40\%), P40 (+), P63 (+). With further imaging scan, the patient was diagnosed as SCC (IV stage), with multiple lymph node metastasis (including retroperitoneal, bilateral neck and supraclavicular fossa). Next-generation sequencing was conducted, and a rare mutation-EGFR R748T-was identified (Fig. 1a). Notably, it was only one reported in an ASCO abstract that an early stage patient with this mutation was treated with erlotinib as postoperative adjuvant therapy and had 54.4 months disease-free survival (DFS) [10]. At the same time, the EGFR R748T mutation located in the kinase domain of EGFR. Therefore, we believe that this mutation is an EGFR-activating oncogenic mutation. However, Simultaneously, The PD-L1 expression assessed by VENTANA PD-L1 (SP263) Assay showed more than $50 \%$ of tumor cells exhibit positive (Fig. 1b). Consideration of the possibility of primary resistance to EGFR-TKIs and multiple metastases of the patient, we decided to try the immuno-chemo combination therapy. The patient thus received $200 \mathrm{mg}$ of pembrolizumab with nabpaclitaxel $\left(220 \mathrm{mg} / \mathrm{m}^{2}\right)$ and nedaplatin $\left(80 \mathrm{mg} / \mathrm{m}^{2}\right)$. Soon, CT scan revealed shrinkage of the tumor in inferior lobe of right lung and lung recruitment (Fig. 1c). During the period of first administration, the patient appeared moderate gastrointestinal adverse reaction and III grade myelosuppression. After symptomatic treatment, patient's adverse reaction symptoms were relieved. Then we reduced the nabpaclitaxel dosage to $180 \mathrm{mg} / \mathrm{m}^{2}$. After treatment two cycles, imaging showed the neoplasm continuously reduced (Fig. 1C), and the patient was evaluated as partial response (PR). The treatment has lasted 2 months and the patient is still in follow-up.

\section{Discussion And Conclusions}

Review of some immunotherapy clinical trials that have included EGFR-mutant patients consistently demonstrates lack of improved clinical outcomes for this population $[3,11,12]$. In a phase II trial of untreated, EGFR-mutant, PD-L1 $\geq 1 \%$ NSCLC, none of the 11 patients responded to Pembrolizumab except for a patient whose EGFR-positive status was erroneous. Furthermore, this study included $73 \%$ of patients with PD-L1 $\geq 50 \%$, thus illustrating the poor response in EGFR-mutated NSCLC even with high PD-L1 expression [3]. Several reasons to these poor outcomes have been identified, such as the association of EGFR mutation with low tumor mutation burden (TMB) and the lack of T cell infiltration while PD-L1 expression is variable $[2,13,14]$. Nevertheless, some studies showed that patients with uncommon EGFR (including G719X, L861Q, S768I, and Ex20 ins) mutations have a good immunotherapy potential [15-17]. Because these EGFR mutations showed higher rates of concomitant PD-L1 expression and CD8 + TILs within the tumor microenvironment than the proportion in patients with classic sensitive mutations [7]. Therefore, immunotherapy for patients with rare EGFR mutations and its mechanism research are interesting direction.

To our best knowledge, there is no report about immuno-chemo therapy on patient with EGFR R748T mutation and PD-L1 high expression. The evidence presented in this case provides a feasible therapy for some patients who harbor a rare EGFR mutation (except for G719X, L861Q, S768I, and Ex20 ins) with high PD-L1 expression. However, the effect of immuno-chemo therapy to EGFR rare mutation, especially 
its side effect, should be further investigated in subsequent studies. In brief, more studies are needed for better understanding of immune checkpoint inhibitors in rare EGFR mutation NSCLC.

\section{Declarations}

\section{Ethics approval and consent to participate}

Ethics approval and consent to participate were obtained.

\section{Consent for publication}

All co-authors consent for this publication.

\section{Competing interests}

None of the authors have conflicts of interest to disclose.

\section{Funding}

No funding was received for this work.

\section{Authors' contributions}

Conception/Design: Qianqian Duan, ZhiGang Liu, Ruifang Sun

Provision of study material or patients: Ruifang Sun, ZhiGang Liu, Guangyan Lei

Collection of data: Qianqian Duan, ZhiGang Liu

Manuscript writing: Ruifang Sun, Qianqian Duan

Final approval of manuscript: Ruifang Sun, Qianqian Duan, Guangyan Lei, Zhigang Liu

\section{Availability of data and material}

Not applicable

\section{Acknowledgements}

Not applicable

\section{References}

1. Herbst RS, Morgensztern D, Boshoff $C$. The biology and management of non-small cell lung cancer. Nature. 2018;553(7689):446-54. doi:10.1038/nature25183. 
2. Gainor JF, Shaw AT, Sequist LV, Fu X, Azzoli CG, Piotrowska Z, Huynh TG, Zhao L, Fulton L, Schultz KR, Howe E, Farago AF, Sullivan RJ, Stone JR, Digumarthy S, Moran T, Hata AN, Yagi Y, Yeap BY, Engelman JA, Mino-Kenudson M. EGFR Mutations and ALK Rearrangements Are Associated with Low Response Rates to PD-1 Pathway Blockade in Non-Small Cell Lung Cancer: A Retrospective Analysis. Clinical cancer research: an official journal of the American Association for Cancer Research. 2016;22(18):4585-93. doi:10.1158/1078-0432.ccr-15-3101.

3. Lisberg A, Cummings A, Goldman JW, Bornazyan K, Reese N, Wang T, Coluzzi P, Ledezma B, Mendenhall M, Hunt J, Wolf B, Jones B, Madrigal J, Horton J, Spiegel M, Carroll J, Gukasyan J, Williams T, Sauer L, Wells C, Hardy A, Linares P, Lim C, Ma L, Adame C, Garon EB. A Phase II Study of Pembrolizumab in EGFR-Mutant, PD-L1+, Tyrosine Kinase Inhibitor Naïve Patients With Advanced NSCLC. Journal of thoracic oncology: official publication of the International Association for the Study of Lung Cancer. 2018;13(8):1138-45. doi:10.1016/j.jtho.2018.03.035.

4. Recondo G, Facchinetti F, Olaussen KA, Besse B, Friboulet L. Making the first move in EGFR-driven or ALK-driven NSCLC: first-generation or next-generation TKI? Nature reviews Clinical oncology. 2018;15(11):694-708. doi:10.1038/s41571-018-0081-4.

5. Hsu KH, Huang YH, Tseng JS, Chen KC, Ku WH, Su KY, Chen JJW, Chen HW, Yu SL, Yang TY, Chang GC. High PD-L1 expression correlates with primary resistance to EGFR-TKIs in treatment naïve advanced EGFR-mutant lung adenocarcinoma patients. Lung cancer (Amsterdam Netherlands). 2019;127:37-43. doi:10.1016/j.lungcan.2018.11.021.

6. Zhang Y, Zeng Y, Liu T, Du W, Zhu J, Liu Z, Huang JA. The canonical TGF-beta/Smad signalling pathway is involved in PD-L1-induced primary resistance to EGFR-TKIs in EGFR-mutant non-smallcell lung cancer. Respir Res. 2019;20(1):164. doi:10.1186/s12931-019-1137-4.

7. Chen K, Cheng G, Zhang F, Zhu G, Xu Y, Yu X, Huang Z, Fan Y. PD-L1 expression and T cells infiltration in patients with uncommon EGFR-mutant non-small cell lung cancer and the response to immunotherapy. Lung cancer (Amsterdam Netherlands). 2020;142:98-105. doi:10.1016/j.lungcan.2020.02.010.

8. Mhanna L, Guibert N, Milia J, Mazieres J. (2019) When to Consider Immune Checkpoint Inhibitors in Oncogene-Driven Non-Small Cell Lung Cancer? Current treatment options in oncology 20 (7):60. doi:10.1007/s11864-019-0652-3.

9. Zhang T, Wan B, Zhao Y, Li C, Liu H, Lv T, Zhan P, Song Y. Treatment of uncommon EGFR mutations in non-small cell lung cancer: new evidence and treatment. Translational lung cancer research. 2019;8(3):302-16. doi:10.21037/tlcr.2019.04.12.

10. Shepherd FA, Eberhardt WEE, Altorki NK, O'Brien MER, Wang J, Wu J, Gill S, Iwata K, Richardson FC, Horan JD, Foley MA, Kelly K. Common and rare EGFR mutations (EGFRm) in the RADIANT trial: Final follow-up with 5 year data. J Clin Oncol. 2015;33(15_suppl):7539-9. doi:10.1200/jco.2015.33.15_suppl.7539.

11. Mazieres J, Drilon A, Lusque A, Mhanna L, Cortot AB, Mezquita L, Thai AA, Mascaux C, Couraud S, Veillon R, Van den Heuvel M, Neal J, Peled N, Früh M, Ng TL, Gounant V, Popat S, Diebold J, Sabari J, 
Zhu VW, Rothschild SI, Bironzo P, Martinez-Marti A, Curioni-Fontecedro A, Rosell R, Lattuca-Truc M, Wiesweg M, Besse B, Solomon B, Barlesi F, Schouten RD, Wakelee H, Camidge DR, Zalcman G, Novello S, Ou SI, Milia J, Gautschi O. Immune checkpoint inhibitors for patients with advanced lung cancer and oncogenic driver alterations: results from the IMMUNOTARGET registry. Annals of oncology: official journal of the European Society for Medical Oncology. 2019;30(8):1321-8. doi:10.1093/annonc/mdz167.

12. Garassino MC, Cho BC, Kim JH, Mazières J, Vansteenkiste J, Lena H, Corral Jaime J, Gray JE, Powderly J, Chouaid C, Bidoli P, Wheatley-Price P, Park K, Soo RA, Huang Y, Wadsworth C, Dennis PA, Rizvi NA. Durvalumab as third-line or later treatment for advanced non-small-cell lung cancer (ATLANTIC): an open-label, single-arm, phase 2 study. The Lancet Oncology. 2018;19(4):521-36. doi:10.1016/s1470-2045(18)30144-x.

13. Lin A, Wei T, Meng H, Luo P, Zhang J. Role of the dynamic tumor microenvironment in controversies regarding immune checkpoint inhibitors for the treatment of non-small cell lung cancer (NSCLC) with EGFR mutations. Mol Cancer. 2019;18(1):139. doi:10.1186/s12943-019-1062-7.

14. Dong ZY, Zhang JT, Liu SY, Su J, Zhang C, Xie Z, Zhou Q, Tu HY, Xu CR, Yan LX, Li YF, Zhong WZ, Wu YL. EGFR mutation correlates with uninflamed phenotype and weak immunogenicity, causing impaired response to PD-1 blockade in non-small cell lung cancer. Oncoimmunology. 2017;6(11):e1356145. doi:10.1080/2162402x.2017.1356145.

15. Gettinger S, Horn L, Jackman D, Spigel D, Antonia S, Hellmann M, Powderly J, Heist R, Sequist LV, Smith DC, Leming P, Geese WJ, Yoon D, Li A, Brahmer J. Five-Year Follow-Up of Nivolumab in Previously Treated Advanced Non-Small-Cell Lung Cancer: Results From the CA209-003 Study. Journal of clinical oncology: official journal of the American Society of Clinical Oncology. 2018;36(17):1675-84. doi:10.1200/jco.2017.77.0412.

16. Yoshida H, Kim YH, Ozasa H, Nagai H, Sakamori Y, Tsuji T, Nomizo T, Yasuda Y, Funazo T, Hirai T. Nivolumab in non-small-cell lung cancer with EGFR mutation. Annals of oncology: official journal of the European Society for Medical Oncology. 2018;29(3):777-8. doi:10.1093/annonc/mdx745.

17. Yamada T, Hirai S, Katayama Y, Yoshimura A, Shiotsu S, Watanabe S, Kikuchi T, Hirose K, Kubota Y, Chihara Y, Harada T, Tanimura K, Takeda T, Tamiya N, Kaneko Y, Uchino J, Takayama K. Retrospective efficacy analysis of immune checkpoint inhibitors in patients with EGFR-mutated nonsmall cell lung cancer. Cancer medicine. 2019;8(4):1521-9. doi:10.1002/cam4.2037.

\section{Figures}


a

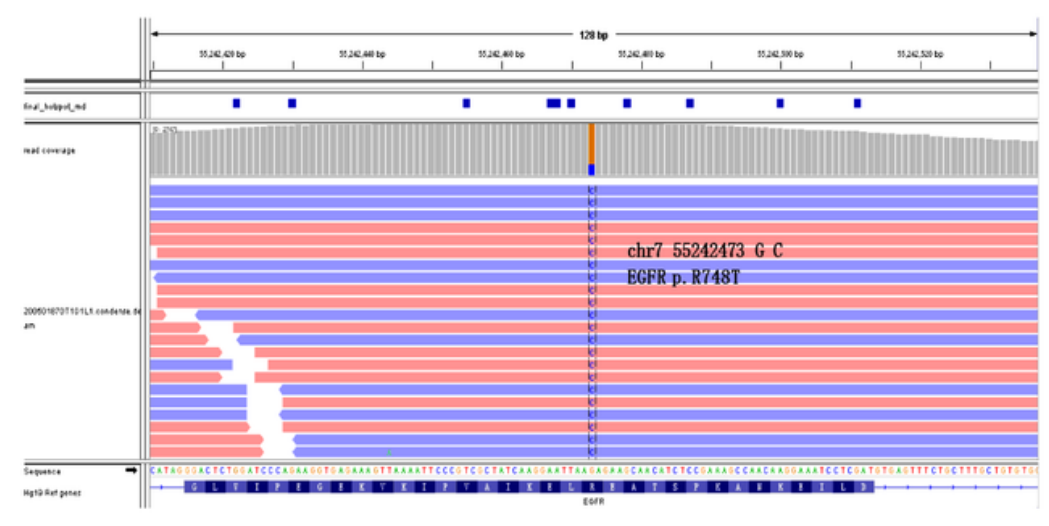

$\mathrm{b}$

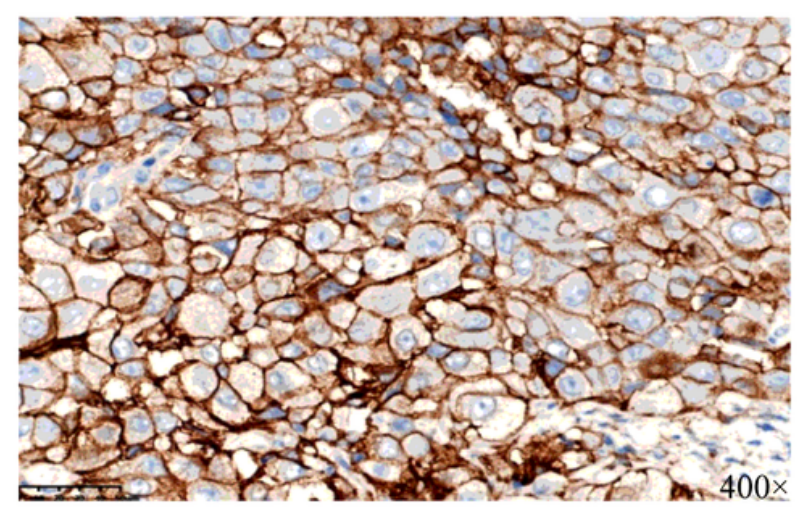

c

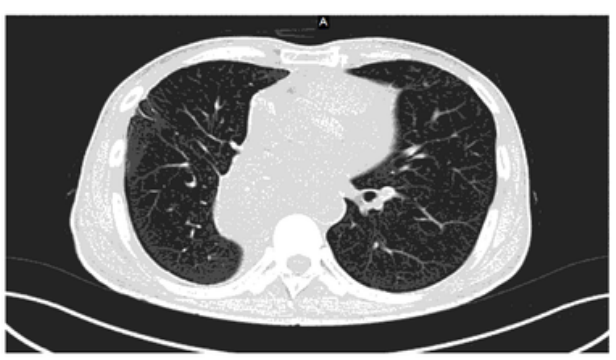

Baseline

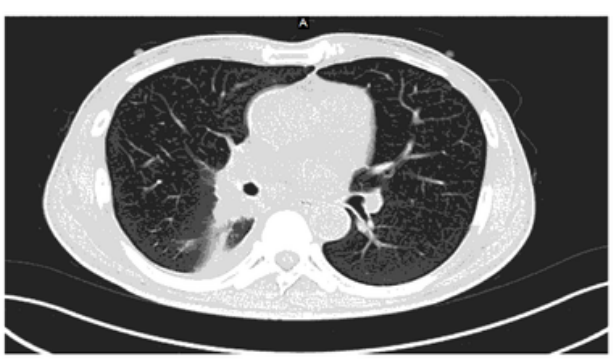

One month

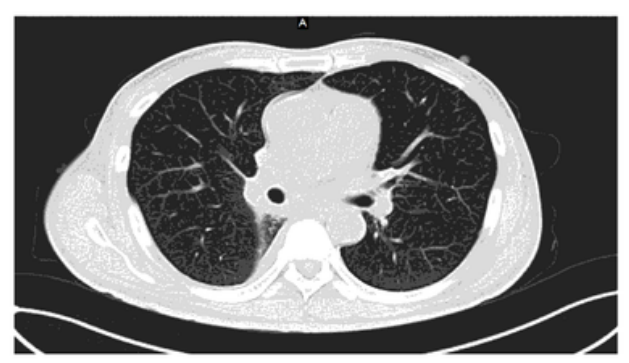

Two months

Figure 1

(a): A rare mutation in EGFR gene exon 19 (EGFR p. R748T). (b): PD-L1 expression result. (c): Computed tomography results indicating tumor response during chemo-immuno combination therapies. 